\title{
Estimation of annual compound growth rates of guava (Psidium guajava L.) fruit in Haryana using Non linear model
}

\author{
Pardeep Panghal \\ Department of Mathematics and Statistics, Chaudhary Charan Singh Hisar Agriculture \\ University Hisar-125004 (Haryana), India \\ Manoj Kumar* \\ Department of Mathematics and Statistics, Chaudhary Charan Singh Hisar Agriculture \\ University Hisar-125004 (Haryana), India \\ Sarita Rani \\ Department of Mathematics and Statistics, Chaudhary Charan Singh Hisar Agriculture \\ University Hisar-125004 (Haryana), India
}

*Corresponding author. E-mail: m25424553@gmail.com

\begin{abstract}
Computation of growth rates plays an important role in agricultural and economic research to study growth pattern of a various commodities. Many of the research workers used the parametric approach for computation of annual growth rate but not use the concept of non-linear model. In this paper, an attempt has been made to study growth rates of guava for three districts (Hisar, and Kurukshetra) and Haryana state as a whole using different non-linear models. The time series data on annual area and production of guava (Psidium guajava L.) in different districts of Haryana from 1990-91 to 2015-16 were collected to fit non linear models. Growth rates were computed through best fitted non-linear models. It was found that Logistic model could be best fit for computation of growth rates of area for guava fruit in Hisar and Kurukshetra district and Haryana state as a whole whereas Gompertz model was best fit for Yamunanagar district based on high $\mathrm{R}^{2}$ and least MSE and RMSE values. It was also observed that monomolecular model was best fit for production of guava fruits in Hisar and Yamunanagar district whereas Logistic model was best fit for production of guava fruit in Kurukshetra and Haryana state as a whole because of high $\mathrm{R}^{2}$ and least MSE and RMSE values. $R$ and excel software have been used for fitting the non linear model and computation of growth rates for area and production of guava fruit for the year 1990-91 to 2015-16. None has been used the non linear model growth model for computation of annual growth rate of guava fruit for area and production of Haryana state. But in this work non linear growth model has been used for computation of growth rate instead of parametric approaches.
\end{abstract}

Keywords: Annual growth rate, Coefficient of determination, Non linear model, Relative mean square error

\section{INTRODUCTION}

Guava (Psidium guajava L.) is one of the important commercial fruit crops in India and introduced in $17^{\text {th }}$ century. It is a rich source of vitamin $\mathrm{C}$, pectin, calcium and phosphorus and is used for the preparation of processed products like jams, jellies and nectar. Guava and its plant parts have great medicinal values for curing diabetes and diarrhoea etc. Leaves of guava are used for curing diarrhoea and also for dyeing and tanning. It is grown in both tropical and sub-tropical region up to $1,500 \mathrm{~m}$ above sea level however good quality guava are produced in river basins. In India, total area under guava was 254.87 thousand hectare in 2015-16 and total production was 4047.79 thou-

\section{Article Info}

https://doi.org/

10.31018/jans.v11i4.2175

Received: October 7, 2019

Revised: November 12, 2019

Accepted: November 17, 2019

\section{How to Cite}

Panghal, P. et al. (2019). Estimation of annual compound growth rates of guava (Psidium guajava L.) fruit in Haryana using Non linear model. Journal of Applied and Natural Science, 11(4): 778 - 784 https://doi.org/10.31018/ jans.v11i4.2175 
growth pattern of a particular commodity. Many research workers have studied the growth rates for area, production and productivity of various agricultural commodities (Rajarathinam et al., 2010, Acharya, et al., 2012, Singh, et al. 2018, Singh, et al., 2019 and Kumar, 2019) on the usual parametric approach. Prajneshu and Chadran (2005) pointed that method of computation of growth rates on the basis of semi-logarithmic growth model has a number of serious lapses and therefore the conclusions drawn are not statistically sound. Keeping in view the above the present study has been undertaken to estimate the compound annual growth rates for area and production for three individual districts (Hisar, Yamunanagar and Kurukshetra) and Haryana state on the basis of non linear growth models like Logistic, Monomolecular and Gompertz model.

\section{MATERIALS AND METHODS}

Non linear growth models viz. Logistic model, Monomolecular and the Gompertz model were used to estimate the compound annualgrowth rates of area and production of guava fruit in Haryana State. The type of model needed in a specific situation depends on the type of growth that occurs. In general, growth models are mechanistic in nature rather than empirical. The descriptions of studied models are as:

Monomolecular model: This model describe the progress of a growth situation in which it is believed that rate of growth at any time is proportional to resource yet to be achieved, i.e.

$$
\frac{a y}{d t}=a(c-y)
$$

Where $\mathrm{a}$ and $\mathrm{c}$ are the intrinsic growth rate and carrying capacity of the system, On integration, we get the model

$y(t)=c-(c-b)^{*} \exp \left(-a^{*} t\right)+e(t)$,

where, $y_{0}$ is the value of $y(t)$ at $t=0$.

This model is also called negative exponential model (Campbell and Madden, 1990).

Logistic Model: It is given by the

$$
\frac{d y}{d t}=a^{2} y\left(1-\frac{y}{c}\right) \text {, }
$$

on integration, we get

$\mathrm{y}(\mathrm{t})=\mathrm{c} /\left(1+\mathrm{b}^{*} \exp \left(-\mathrm{a}^{*} \mathrm{t}\right)\right)$

The graph of $y(t)$ versus $t$ is elongated. S-shaped and the curve is symmetrical about its Inflexion.

Gompertz Model: This model has sigmoid type of behavior and is found quite useful in the biological work. However, unlike logistic model, this is not symmetric about its point of inflexion. This model is given by the differential equation.

$$
\frac{a y}{d t}=a y \operatorname{Ln}(c / y)
$$

Where, the symbol "Ln" denotes "natural logarithm" Integration of this equation yields $y(t)=c^{*} \exp \left(-b^{*} \exp \left(-a^{*} t\right)\right)+e(t)$, where $y(t)$ denotes the variable under study at time $t$, ' $a$ ' denote the intrinsic growth rate, 'c' the carrying capacity of the system

Fitting of non-linear growth model: In nonlinear model it is not possible to solve the non-linear equations exactly the only alternative is to employ iterative procedures. Parameter estimate in nonlinear regression can be obtained by the method of least squares. There are three methods to obtain approximate analytical solutions by employing iterative procedures:

Linearization (Taylor series) method.

Steepest descent method

Levenberg-Marquardt's method

The details of these methods along with their merits and demerits are given in Draper and Smith (1998). The linearization method uses the results of linear least square theory in a succession of stages. However, neither this method nor the steepest descent method is ideal. The steepest descent method is able to converge on true parameter values even though initial trial values are far from the true parameter values, but this convergence tends to be very slow at the later stages of the iterative process.

On the other hand, the linearization method will converge very rapidly provided the vicinity of the true parameter values has been reached, but if initial trial values are too far removed, convergence may not occur at all. Mostly used method for computing non-linear least squares estimators is the Levenberg Marquardt's method. The Levenberg-Marquardt method combines two minimization methods. The gradient descent method and the Gauss-Newton method. In the gradient descent method, the sum of the squared errors is reduced by updating the parameters in the steepest-descent direction. In the Gauss-Newton method, the sum of the squared errors is reduced by assuming the least squares function is locally quadratic, and finding the minimum of the quadratic. It is good in the sense that it almost always converges and does not 'slow down' at the latter part of the iterative process.

Goodness of fit for criteria for selection of model: There is no single technique to evaluate goodness of fit criterion to access the suitability of models fitted. This is generally assessed by the coefficient of determination, $R^{2}$. In addition to R2, root mean square error (RMSE) and mean absolute error were also used as the selection criteria for evaluation of model. The details of the criteria is given below

Coefficient of determination (R2): It is calculated using the following formula

$$
R^{2}=1-\frac{R S S}{T S S}
$$

Where RSS is the residual sum of square, TSS is the total sum of square. The coefficient of deter- 
mination lies always between 0 to 1 , and the model is considered to be best fitted if R2 is close to unity.

The mean squared error (MSE): It is the average of the squared difference between estimated value and observed value and is given as

$$
M S E=\frac{\sum\left(y_{i}-\bar{y}\right)^{2}}{n}
$$

Root mean square error (RMSE): It is a kind of generalized standard deviation and was calculated as follows:

$$
\text { RMSE }=\sqrt{\frac{\sum\left(y_{\mathrm{i}}-\hat{y}\right)^{2}}{n}}
$$

RMSE value is one of the most important criteria to compare the suitability of used growth curve models. Therefore, the best model is the one with the lowest RMSE.

Compound growth rate and annual growth rate: CGR should be computed by first identifying that which model is best fitted for the path followed by response variables over time. For Monomolecular, Logistic and Gompertz models, annual growth rates pertaining to the period $\mathrm{Ri}$, $(\mathrm{i}=0,1$, $2, \ldots \ldots, n-1)$ where $n=$ no. of data points.

Monomolecular model: $\mathrm{Rt}=\mathrm{a}^{*}(\mathrm{c} / \mathrm{y}(\mathrm{t})-1)$

Logistic model: $\quad \mathrm{Rt}=\mathrm{a}^{*}(1-\mathrm{y}(\mathrm{t}) / \mathrm{c})$

Gompertz model: $\quad \mathrm{Rt}=\mathrm{a}^{*} \ln (\mathrm{c} / \mathrm{y}(\mathrm{t}))$

Where, $a=$ Intrinsic Growth rate, $c=$ Some limiting growth value or carrying capacity $y(t)=$ response variable at any time t. We can obtain
Compound Growth rate over a given time period by taking arithmetic mean or average.

SPSS, R and Excel has been used to fit the models and computation of annual growth rate.

\section{RESULTS AND DISCUSSION}

The perusal of data presented in Table 1 revealed the area and production of guava fruit in the district of Hisar, Yamunanagar, Kurukshetra and Haryana state as a whole for the year 1990-91 to 2015-16. The data has been taken from site of Horticultural board Haryana (Anonymous, 2015).

Table 2 shows the parameter estimation and selection criteria for the Hisar, Yamunanagar, Kurukshetra and Haryana state as a whole using different models i.e. Monomolecular, Logistic and Gompertz model for area of Guava from 1990-91 to 2015-16. From the above table it is concluded that Logistic model has maximum value of $R^{2}$ and least value of MSE and RMSE for Hisar, Kurukshetra and Haryana state as a whole. Therefore, Logistic model found to be the best fit for computation of compound growth rates and predicted value for Hisar, Kurukshetra and Haryana State as a whole. From the table, it is also concluded that Gompertz model found to be the best fit for Yamunanagar because of maximum value of $\mathrm{R}^{2}$ and least value of MSE and RMSE and the same was used for computation of growth rate and predicted value of area of Guava in Yamunanagar. Table 3 shows the predicted value and annual

\begin{tabular}{|c|c|c|c|c|c|c|c|c|}
\hline \multirow[t]{2}{*}{ Year } & \multicolumn{2}{|c|}{ Hisar } & \multicolumn{2}{|c|}{ Yamunanagar } & \multicolumn{2}{|c|}{ Kurukshetra } & \multicolumn{2}{|c|}{ Haryana } \\
\hline & $\begin{array}{l}\text { Area } \\
\text { (ha) }\end{array}$ & $\begin{array}{l}\text { Production } \\
\text { (MT) }\end{array}$ & $\begin{array}{l}\text { Area } \\
\text { (ha) }\end{array}$ & $\begin{array}{l}\text { Production } \\
\text { (MT) }\end{array}$ & $\begin{array}{l}\text { Area } \\
\text { (ha) }\end{array}$ & $\begin{array}{l}\text { Production } \\
\text { (MT) }\end{array}$ & $\begin{array}{l}\text { Area } \\
\text { (ha) }\end{array}$ & $\begin{array}{l}\text { Production } \\
(\mathrm{MT})\end{array}$ \\
\hline 1990-91 & 140 & 1100 & 80.6 & 680 & 90.2 & 760 & 1734.55 & 14500 \\
\hline 1991-92 & 165 & 1400 & 89 & 750 & 103 & 850 & 1909 & 15645 \\
\hline 1992-93 & 169 & 1125 & 102 & 1100 & 93 & 515 & 2172 & 16350 \\
\hline 1993-94 & 196 & 1500 & 103 & 1400 & 114 & 670 & 2509 & 22301 \\
\hline 1994-95 & 216 & 2900 & 115 & 1050 & 135 & 1100 & 2778 & 22700 \\
\hline 1995-96 & 258 & 2300 & 127 & 2300 & 152 & 1250 & 3160 & 25500 \\
\hline 1996-97 & 308 & 4100 & 161 & 1550 & 175 & 1200 & 3540 & 25850 \\
\hline 1997-98 & 228 & 1700 & 197 & 1600 & 200 & 1300 & 4062 & 30450 \\
\hline 1998-99 & 263 & 3000 & 218 & 5400 & 229 & 1450 & 4648 & 44771 \\
\hline 1999-00 & 295 & 4000 & 278 & 2012 & 253 & 2018 & 5194 & 43709 \\
\hline 2000-01 & 320 & 3100 & 349 & 2305 & 275 & 2068 & 5728 & 40092 \\
\hline 2001-02 & 328 & 1400 & 387 & 3914 & 280 & 2644 & 5944 & 41226 \\
\hline 2002-03 & 329 & 3300 & 477 & 4107 & 290 & 3010 & 6173 & 54870 \\
\hline 2003-04 & 359 & 3500 & 564 & 1844 & 216 & 2045 & 6026 & 48111 \\
\hline 2004-05 & 324 & 3305 & 268 & 2734 & 185 & 1887 & 3998 & 40780 \\
\hline 2005-06 & 344 & 2350 & 300 & 2073 & 200 & 1072 & 4622 & 34878 \\
\hline 2006-07 & 455 & 2140 & 319 & 1622 & 214 & 1080 & 5346 & 39725 \\
\hline 2007-08 & 503 & 2950 & 388 & 1781 & 227 & 1020 & 6133 & 42199 \\
\hline 2008-09 & 576 & 1750 & 461 & 2065 & 227 & 534 & 6973 & 48209 \\
\hline 2009-10 & 614 & 2300 & 516 & 1846 & 249 & 510 & 7817 & 55840 \\
\hline 2010-11 & 865 & 3140 & 530 & 5460 & 351 & 2934 & 9339 & 71612 \\
\hline 2011-12 & 918 & 2820 & 567 & 4390 & 365 & 1250 & 9651 & 87056 \\
\hline 2012-13 & 973 & 12610 & 679 & 8142 & 405 & 1585 & 10379 & 107559 \\
\hline 2013-14 & 982 & 10005 & 735 & 8800 & 422 & 2850 & 10669 & 125043 \\
\hline 2014-15 & 976 & 12200 & 785 & 7000 & 426 & 3805 & 10843 & 136730 \\
\hline 2015-16 & 983 & 13130 & 821 & 12800 & 468 & 6259 & 11211 & 152184 \\
\hline
\end{tabular}

Table 1. Area and production of guava fruit in different districts of Haryana. 
Panghal, P. et al. / J. Appl. \& Nat. Sci. 11(4): 778 - 784 (2019)

Table 2. Parameter estimation and selection criteria for fitting of Non-linear growth model for area of guava in Hisar district of Haryana during period 1990-91 to 2015-16.

\begin{tabular}{|c|c|c|c|}
\hline \multicolumn{4}{|c|}{ Hisar } \\
\hline Parameters & Monomolecular & Logistic & Gompertz \\
\hline A & $6.91 \times 10^{-05}$ & 0.086 & 0.009 \\
\hline B & -14.39 & 285.74 & 11.29 \\
\hline C & 513562.70 & 34338.49 & 8764795 \\
\hline R2 & 0.849 & 0.942 & 0.941 \\
\hline MSE & 14288.86 & 5452.47 & 5616.24 \\
\hline RMSE & 119.53 & 73.84 & 74.94 \\
\hline \multicolumn{4}{|c|}{ Yamunanagar } \\
\hline$\overline{\mathbf{A}}$ & 0.007 & 0.084 & 0.017 \\
\hline B & 5.57 & 46.38 & 6.00 \\
\hline C & 194072.60 & 5088.61 & 38591.13 \\
\hline R2 & 0.868 & 0.885 & 0.886 \\
\hline MSE & 7461.49 & 6530.49 & 6447.45 \\
\hline RMSE & 86.37 & 80.811 & 80.29 \\
\hline \multicolumn{4}{|c|}{ Kurukshetra } \\
\hline$\overline{\mathbf{A}}$ & 0.008 & 0.053 & 0.006 \\
\hline B & 75.73 & 9293644 & 9417 \\
\hline C & 87357.11 & 10203.30 & 1310758.00 \\
\hline R2 & 0.784 & 0.811 & 0.808 \\
\hline MSE & 2725.651 & 2379.72 & 2415.046 \\
\hline RMSE & 52.20777 & 48.78237 & 49.14312 \\
\hline \multicolumn{4}{|c|}{ Haryana } \\
\hline$\overline{\mathbf{A}}$ & 0.008 & 0.066 & 0.009 \\
\hline B & 924.74 & 134.52 & 8.18 \\
\hline C & 2618520.00 & 296053.90 & 7352944.00 \\
\hline R2 & 0.895 & 0.92 & 0.92 \\
\hline MSE & 999292.40 & 758216.10 & 758762.80 \\
\hline RMSE & 999.65 & 870.76 & 871.07 \\
\hline
\end{tabular}

Table 3. Predicted value and annual growth rate on the basis of best fitted model for area of Guava in Hisar, Yamunanagar, Kurukshetra and Haryana state as a whole from 1990-91 to 2015-16.

\begin{tabular}{|c|c|c|c|c|c|c|c|c|}
\hline \multirow[b]{2}{*}{ Years } & \multicolumn{2}{|c|}{ Hisar } & \multicolumn{2}{|c|}{ Yamunanagar } & \multicolumn{2}{|c|}{ Kurukshetra } & \multicolumn{2}{|c|}{ Total Haryana } \\
\hline & $\begin{array}{l}\text { Logistic } \\
\text { Predicted } \\
\text { Area(ha) }\end{array}$ & $\begin{array}{l}\text { Annual } \\
\text { Growth Rate } \\
\text { through Lo- } \\
\text { gistic Model }\end{array}$ & $\begin{array}{c}\text { Gompertz } \\
\text { Predicted } \\
\text { Area(ha) }\end{array}$ & $\begin{array}{l}\text { Annual Growth } \\
\text { Rate through } \\
\text { Gompertz Model }\end{array}$ & $\begin{array}{c}\text { Logistic } \\
\text { Predicted } \\
\text { Area(ha }\end{array}$ & $\begin{array}{l}\text { Annual } \\
\text { Growth Rate } \\
\text { through Lo- } \\
\text { gistic Model }\end{array}$ & & $\begin{array}{c}\text { Annual } \\
\text { Growth Rate } \\
\text { through Lo- } \\
\text { gistic Model }\end{array}$ \\
\hline 1990-91 & 130.51 & 0.0857 & 105.62 & 0.1003 & 115.79 & 0.0524 & 2331.85 & 0.0655 \\
\hline 1991-92 & 142.23 & 0.0856 & 116.56 & 0.0986 & 122.13 & 0.0524 & 2488.97 & 0.0654 \\
\hline $1992-93$ & 155.00 & 0.0856 & 128.43 & 0.0970 & 128.81 & 0.0523 & 2656.60 & 0.0654 \\
\hline $1993-94$ & 168.91 & 0.0856 & 141.28 & 0.0954 & 135.85 & 0.0523 & 2835.40 & 0.0654 \\
\hline 1994-95 & 184.06 & 0.0855 & 155.17 & 0.0938 & 143.28 & 0.0523 & 3026.11 & 0.0653 \\
\hline $1995-96$ & 200.56 & 0.0855 & 170.15 & 0.0922 & 151.12 & 0.0522 & 3229.50 & 0.0653 \\
\hline $1996-97$ & 218.54 & 0.0855 & 186.30 & 0.0907 & 159.38 & 0.0522 & 3446.41 & 0.0652 \\
\hline 1997-98 & 238.11 & 0.0854 & 203.66 & 0.0892 & 168.10 & 0.0521 & 3677.70 & 0.0652 \\
\hline 1998-99 & 259.42 & 0.0854 & 222.32 & 0.0877 & 177.30 & 0.0521 & 3924.31 & 0.0651 \\
\hline $1999-00$ & 282.62 & 0.0853 & 242.32 & 0.0862 & 186.99 & 0.0520 & 4187.21 & 0.0651 \\
\hline 2000-01 & 307.88 & 0.0852 & 263.75 & 0.0848 & 197.22 & 0.0520 & 4467.46 & 0.0650 \\
\hline 2001-02 & 335.37 & 0.0852 & 286.67 & 0.0833 & 208.01 & 0.0519 & 4766.16 & 0.0649 \\
\hline 2002-03 & 365.29 & 0.0851 & 311.14 & 0.0819 & 219.38 & 0.0519 & 5084.48 & 0.0649 \\
\hline 2003-04 & 397.86 & 0.0850 & 337.25 & 0.0806 & 231.38 & 0.0518 & 5423.67 & 0.0648 \\
\hline 2004-05 & 433.28 & 0.0849 & 365.05 & 0.0792 & 244.04 & 0.0517 & 5785.03 & 0.0647 \\
\hline 2005-06 & 471.82 & 0.0848 & 394.61 & 0.0779 & 257.39 & 0.0517 & 6169.96 & 0.0646 \\
\hline 2006-07 & 513.73 & 0.0847 & 426.02 & 0.0766 & 271.47 & 0.0516 & 6579.93 & 0.0645 \\
\hline 2007-08 & 559.30 & 0.0846 & 459.34 & 0.0753 & 286.31 & 0.0515 & 7016.47 & 0.0644 \\
\hline 2008-09 & 608.85 & 0.0845 & 494.65 & 0.0741 & 301.97 & 0.0514 & 7481.23 & 0.0643 \\
\hline $2009-10$ & 662.70 & 0.0843 & 532.01 & 0.0728 & 318.49 & 0.0513 & 7975.92 & 0.0642 \\
\hline $2010-11$ & 721.20 & 0.0842 & 571.49 & 0.0716 & 335.91 & 0.0513 & 8502.36 & 0.0641 \\
\hline 2011-12 & 784.76 & 0.0840 & 613.17 & 0.0704 & 354.28 & 0.0512 & 9062.45 & 0.0640 \\
\hline $2012-13$ & 853.77 & 0.0839 & 657.12 & 0.0692 & 373.66 & 0.0511 & 9658.20 & 0.0638 \\
\hline 2013-14 & 928.68 & 0.0837 & 703.40 & 0.0681 & 394.10 & 0.0510 & 10291.71 & 0.0637 \\
\hline 2014-15 & 1009.96 & 0.0835 & 752.09 & 0.0669 & 415.65 & 0.0508 & 10965.18 & 0.0636 \\
\hline 2015-16 & 1098.13 & 0.0832 & 803.25 & 0.0658 & 438.39 & 0.0507 & 11680.92 & 0.0634 \\
\hline
\end{tabular}


Panghal, P. et al. / J. Appl. \& Nat. Sci. 11(4): 778 - 784 (2019)

Table 4. Predicted value and annual growth rate on the basis of best fitted model for Production of Guava in Hisar, Yamunanagar, Kurukshetra and Haryana state as a whole from 1990-91 to 2015-16.

\begin{tabular}{|c|c|c|c|c|c|c|c|c|}
\hline \multirow[b]{2}{*}{ Years } & \multicolumn{2}{|c|}{ Hisar } & \multicolumn{2}{|c|}{ Yamunanagar } & \multicolumn{2}{|c|}{ Kurukshetra } & \multicolumn{2}{|c|}{ Haryana } \\
\hline & $\begin{array}{l}\text { Monomolecu- } \\
\text { lar Predicted } \\
\text { Production } \\
\text { (MT) }\end{array}$ & $\begin{array}{c}\text { Annual Growth } \\
\text { Rate through } \\
\text { Monomolecular } \\
\text { Model }\end{array}$ & $\begin{array}{c}\text { Monomolecu- } \\
\text { lar Predicted } \\
\text { Production } \\
\text { (MT }\end{array}$ & $\begin{array}{c}\text { Annual Growth } \\
\text { Rate through } \\
\text { Monomolecular } \\
\text { Model }\end{array}$ & $\begin{array}{l}\text { Predicted } \\
\text { Production } \\
\text { (MT) }\end{array}$ & $\begin{array}{l}\text { Annual } \\
\text { Growth Rate } \\
\text { through Lo- } \\
\text { gistic Model }\end{array}$ & & $\begin{array}{l}\text { Annual Growth } \\
\text { Rate through } \\
\text { Logistic Model }\end{array}$ \\
\hline $1990-91$ & 2145.43 & 0.0008 & 1902.82 & 0.0009 & 641.50 & 0.0353 & 11049.44 & 0.1020 \\
\hline 1991-92 & 2147.49 & 0.0011 & 1904.76 & 0.0012 & 664.88 & 0.0366 & 12231.04 & 0.1020 \\
\hline $1992-93$ & 2150.30 & 0.0015 & 1907.39 & 0.0016 & 690.04 & 0.0380 & 13539.00 & 0.1020 \\
\hline $1993-94$ & 2154.13 & 0.0021 & 1910.94 & 0.0022 & 717.17 & 0.0395 & 14986.83 & 0.1020 \\
\hline 1994-95 & 2159.33 & 0.0028 & 1915.74 & 0.0029 & 746.53 & 0.0411 & 16589.49 & 0.1020 \\
\hline $1995-96$ & 2166.40 & 0.0038 & 1922.22 & 0.0039 & 778.39 & 0.0428 & 18363.54 & 0.1020 \\
\hline $1996-97$ & 2176.02 & 0.0051 & 1930.97 & 0.0053 & 813.09 & 0.0447 & 20327.29 & 0.1020 \\
\hline $1997-98$ & 2189.12 & 0.0070 & 1942.80 & 0.0071 & 851.03 & 0.0468 & 22501.05 & 0.1020 \\
\hline 1998-99 & 2206.93 & 0.0094 & 1958.78 & 0.0095 & 892.68 & 0.0491 & 24907.27 & 0.1020 \\
\hline 1999-00 & 2231.15 & 0.0126 & 1980.36 & 0.0126 & 938.62 & 0.0516 & 27570.80 & 0.1020 \\
\hline $2000-01$ & 2264.12 & 0.0169 & 2009.53 & 0.0168 & 989.54 & 0.0544 & 30519.16 & 0.1020 \\
\hline 2001-02 & 2308.96 & 0.0226 & 2048.94 & 0.0223 & 1046.31 & 0.0576 & 33782.81 & 0.1020 \\
\hline 2002-03 & 2369.96 & 0.0299 & 2102.18 & 0.0293 & 1109.98 & 0.0611 & 37395.47 & 0.1020 \\
\hline 2003-04 & 2452.95 & 0.0393 & 2174.12 & 0.0383 & 1181.91 & 0.0650 & 41394.47 & 0.1020 \\
\hline 2004-05 & 2565.84 & 0.0512 & 2271.30 & 0.0496 & 1263.80 & 0.0695 & 45821.10 & 0.1020 \\
\hline 2005-06 & 2719.42 & 0.0657 & 2402.61 & 0.0633 & 1357.89 & 0.0747 & 50721.12 & 0.1020 \\
\hline 2006-07 & 2928.36 & 0.0830 & 2580.01 & 0.0797 & 1467.11 & 0.0807 & 56145.12 & 0.1020 \\
\hline 2007-08 & 3212.59 & 0.1029 & 2819.69 & 0.0985 & 1595.43 & 0.0878 & 62149.16 & 0.1020 \\
\hline 2008-09 & 3599.26 & 0.1249 & 3143.52 & 0.1193 & 1748.36 & 0.0962 & 68795.26 & 0.1020 \\
\hline $2009-10$ & 4125.29 & 0.1482 & 3581.03 & 0.1415 & 1933.71 & 0.1064 & 76152.08 & 0.1020 \\
\hline $2010-11$ & 4840.91 & 0.1719 & 4172.14 & 0.1641 & 2163.03 & 0.1190 & 84295.60 & 0.1020 \\
\hline 2011-12 & 5814.42 & 0.1947 & 4970.75 & 0.1861 & 2454.04 & 0.1350 & 93310.02 & 0.1020 \\
\hline 2012-13 & 7138.80 & 0.2157 & 6049.74 & 0.2066 & 2835.53 & 0.1560 & 103288.40 & 0.1020 \\
\hline 2013-14 & 8940.48 & 0.2343 & 7507.52 & 0.2249 & 3357.46 & 0.1847 & 114333.80 & 0.1020 \\
\hline 2014-15 & 11391.49 & 0.2501 & 9477.07 & 0.2407 & 4114.87 & 0.2264 & 126560.50 & 0.1020 \\
\hline 2015-16 & 14725.85 & 0.2632 & 12138.06 & 0.2540 & 5313.54 & 0.2923 & 140094.60 & 0.1020 \\
\hline
\end{tabular}

Table 5. Parameter estimation and selection criteria for fitting of Non-linear growth model for production of Guava Hisar district of Haryana during period 1990-91 to 2015-16.

\begin{tabular}{|c|c|c|c|}
\hline \multicolumn{4}{|c|}{ Hisar } \\
\hline Parameters & Monomolecular & Logistic & Gompertz \\
\hline a & -0.308 & 0.141 & 0.008 \\
\hline b & 2143.90 & $2.81 \times 10^{8}$ & 19.47 \\
\hline c & 2139.69 & $8.87 E+10$ & $7.52 \times 10^{10}$ \\
\hline $\mathbf{R} 2$ & 0.789 & 0.666 & 0.653 \\
\hline MSE & 3005835 & 4753023 & 4940479 \\
\hline RMSE & 1733.73 & 2180.14 & 2222.71 \\
\hline \multicolumn{4}{|c|}{ Yamunanagar } \\
\hline $\mathbf{a}$ & 0.301 & 8.62E-06 & 0.008 \\
\hline b & 1901.38 & 1.00 & 18.00 \\
\hline c & 1897.28 & 0.30 & $2.47 \times 10^{10}$ \\
\hline R2 & 0.791 & 0.787 & 0.674 \\
\hline MSE & 1980197 & 2017401 & 3083415 \\
\hline RMSE & 1407.19 & 1420.35 & 1755.97 \\
\hline \multicolumn{4}{|c|}{ Kurukshetra } \\
\hline $\mathbf{a}$ & $6.18 \times 10^{-5}$ & $4.90 \times 10^{-6}$ & 0.005 \\
\hline b & 539.54 & 1.00 & 13.94 \\
\hline C & 145670.70 & 0.08 & $7.36 \times 10^{8}$ \\
\hline R2 & 0.295 & 0.513 & 0.343 \\
\hline MSE & 1236395 & 853663 & 1151604 \\
\hline RMSE & 1111.93 & 923.93 & 1073.12 \\
\hline \multicolumn{4}{|c|}{ Haryana } \\
\hline $\mathbf{a}$ & $5.44 \times 10^{-5}$ & 0.102 & 0.007 \\
\hline b & -3926.21 & $7.63 E+08$ & 15.48 \\
\hline C & 78076667 & $7.62 \times 10^{12}$ & $4.87 \times 10^{10}$ \\
\hline R2 & 0.734 & 0.895 & 0.885 \\
\hline MSE & $4.15 \times 10^{8}$ & $1.64 \times 10^{8}$ & $1.79 \times 10^{8}$ \\
\hline RMSE & 20371.38 & 12823.79 & 13380.22 \\
\hline
\end{tabular}


Panghal, P. et al. / J. Appl. \& Nat. Sci. 11(4): 778 - 784 (2019)

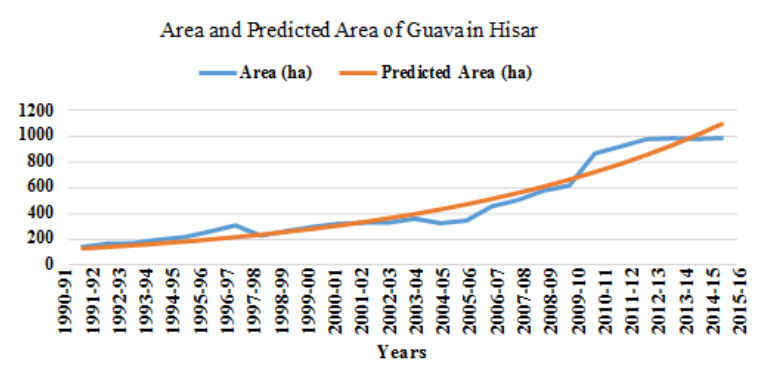

Fig. 1. Showing the actual and predicted value of area of Guava in Hisar district for the year 1990-91 to 2015-16 through Logistic model.

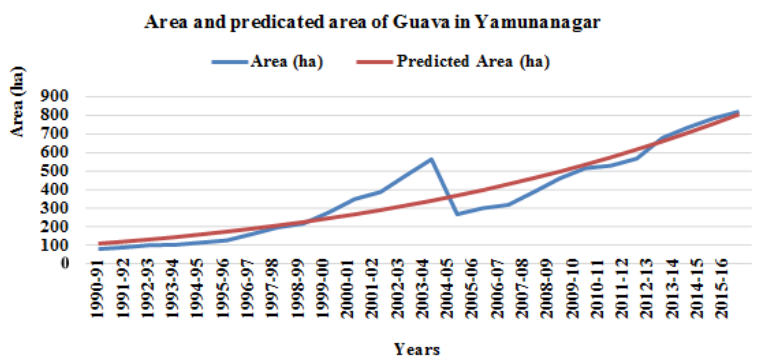

Fig. 2. Showing the actual and predicted value of area of Guava in Yamunanagar district for the year 1990-91 to 2015-16 through Gompertz model.

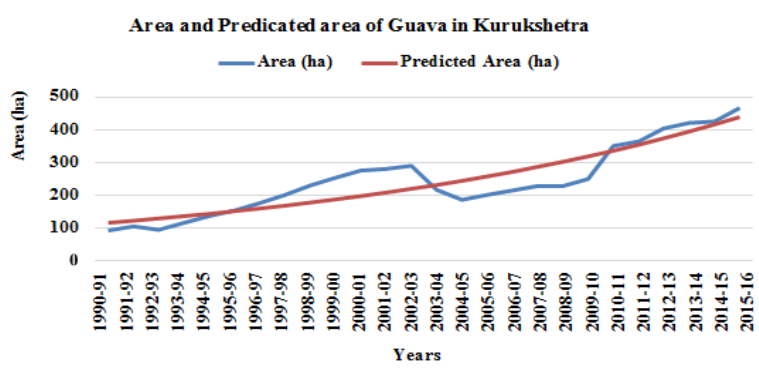

Fig. 3. Actual and predicted value of area of Guava in Kurukshetra district for the year 1990-91 to 201516 through Logistic model.

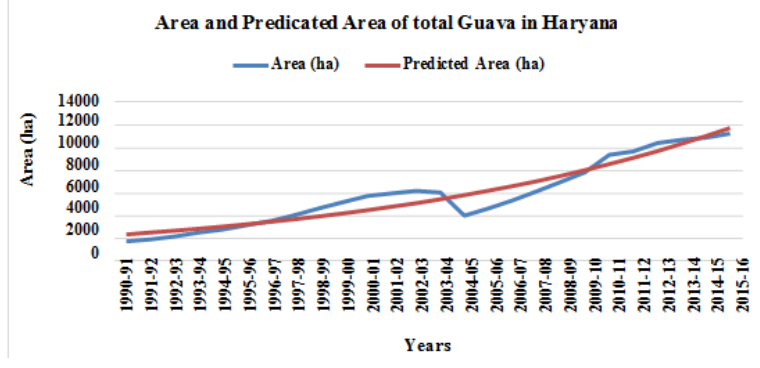

Fig. 4. Showing the actual and predicted value of area of Haryana in Kurukshetra district for the year 1990-91 to 2015-16 through Logistic model.

compound growth rates for area of guava during the time period 1990-91 to 2015-16 in Hisar, Yamunanagar, Kurukshetra district of Haryana and Haryana state as a whole. Since Logistic model was found to be the best fit model for the area of guava in Hisar, Kurukshetra district of Haryana and Haryana state as a whole the same was use to calculate the annual growth rate of in different district respectively. By taking mean value or aver-

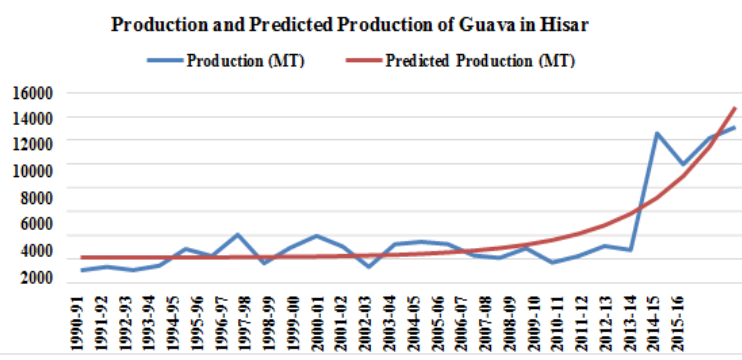

Fig. 5. Actual and predicted value of production of Guava in Hisar district for the year 1990-91 to 201516 through monomolecular model .

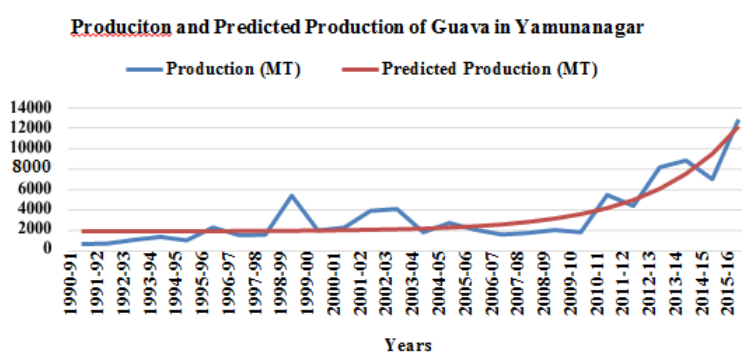

Fig. 6. Actual and predicted value of production of Guava in Yamunanagar district for the year 1990-91 to 2015-16 through Monomolecular model.

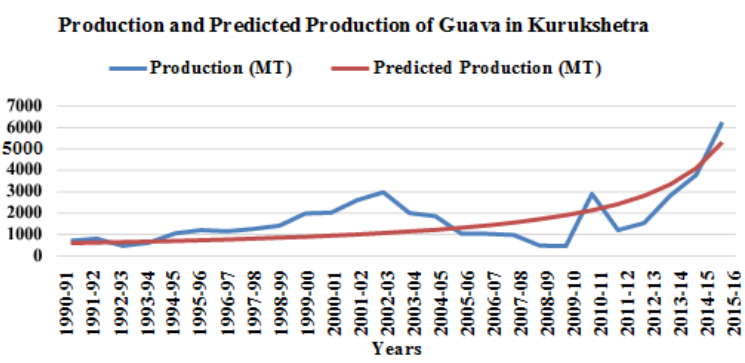

Fig. 7. Actual and predicted value of production of Guava in Yamunanagar district for the year 1990-91 to 2015-16 through Logistic model.

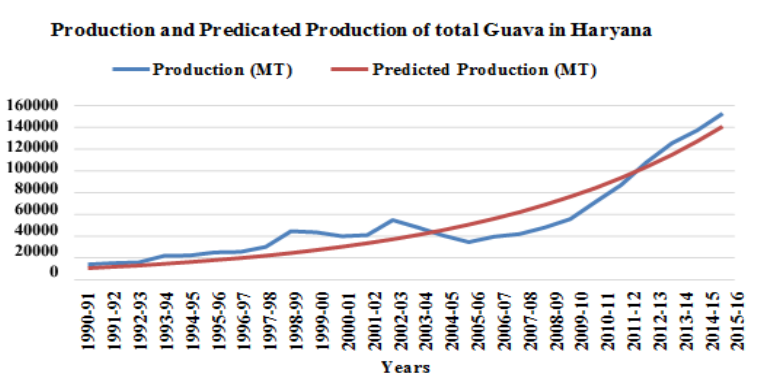

Fig. 8. Actual and predicted value of production of Guava in Haryana State for the year 1990-91 to 2015 -16 through Logistic model.

age value of annual growth rate the average annual growth rate was found to be $8.48 \%, 5.17 \%$ and $6.47 \%$.respectively. Whereas Gompertz model is used for computing calculating annual growth rate of Guava in Yamunanagar and it was observed that mean value or average value of annual growth rate was found to be $8.19 \%$.

Table 4 shows the parameter estimation and selection criteria for the Hisar, Yamunanagar, Ku- 
rukshetra and Haryana state as a whole for different models i.e. Monomolecular, Logistic and Gompertz model for production of Guava from 1990-91 to $2015-16$. From the above table it is concluded that monomolecular model has maximum value of $\mathrm{R}^{2}$ and minimum value of MSE and RMSE for Hisar and Yamunanagar district. Therefore, monomolecular model found to be the best fit for computation of compound growth rates and predicted value for Hisar and Kurukshetra district. It is also observed from the table that logistic model found to be the best fit for Kurukshetra and Haryana state as a whole because of maximum value of $R^{2}$ and minimum value of MSE and RMSE and the same was used for computation of growth rate and predicted value of production of Guava in Kurukshetra and Haryana State as a whole. The figure number from5 to 8 shows the actual and predicted value of production of Guava for Hisar, Yamunanagar, Kurukshetra and Haryana state as a whole on the basis of best fitted model. Table 5 shows the predicted value and annual compound growth rates for production of guava during the time period $1990-91$ to $2015-16$ in Hisar, Yamunanagar, Kurukshetra district and Haryana as a whole state on the basis of best fitted model. It was observed from the table that average annual growth rate for production of guava was found to be7.93\%, $7.62 \%, 8.82 \%$ and $10.20 \%$ for Hisar, Yamunanagar, Kurukshetra district and Haryana as a whole state.

It is observed that Logistic model was the best fit for computation of growth rates of area for guava fruit in Hisar and Kurukshetra district and Haryana state as a whole whereas Gompertz model was best fit for Yamunanagar district based on high $\mathrm{R}^{2}$ and least MSE and RMSE values. It was also observed that monomolecular model was best fit for production of guava fruits in Hisar and Yamunanagar district whereas Logistic model was best fit for production of guava fruit in Kurukshetra and Haryana state as a whole because of high $R^{2}$ and least MSE and RMSE values. Mukherjee et al. (2016) studied the application of non linear growth model for estimation of annual compound growth rates of major pulses in Telangana state and observed that both the Logistic and the Gompertz model gave almost similar results. But in some cases the Logistic model proved to be better fit as compared to the Gompertz model. The estimated compound annual growth rates revealed that the area, production and yield of arhar has shown an increasing trend over the study period but there was a decreasing trend for moong in Telangana state.

\section{Conclusion}

Several packages like R, SAS and SPSS are readily available to fit the non linear growth model for computation of growth rates. In this paper $\mathrm{R}$ and excel software has been used for computation of average compound growth rate of guava fruit. The average annual growth rate for area of guava for Hisar, Kurukshetra, Yamunanagar district of Haryana and Haryana state as a whole was found to be $8.48 \%, 5.17 \%, 8.19 \%$ and $6.47 \%$ respectively, whereas the average annual growth rate for production of guava for the same was to be $7.93 \%, 7.62 \%, 8.82 \%$ and $10.20 \%$.

\section{REFERENCES}

1. Acharya, S.P., Basavaraja H., Kunnall, L.B., Mahajanashetti, S.B. and Bhat, A.R.S. (2012) Growth in area, production and productivity of major crops in Karnataka. Karnataka J. Agric. Sci.,25(4):431-436. https://DOI: 10.15740/HAS/AU/10.4/288-293

2. Anonymous (2015). Department of Horticulture, Government of Haryana. Retrieved from http:// hortharyana.gov.in/en/statisticaldata.pdf

3. Draper, N. R. and H. Smith, (1998). Applied Regression Analysis, 3rd Edn., New York, USA: John Wiley \& Sons.

4. Prajneshu, and Chandran, K.P. (2005). Computation of Compound Growth Rates in Agriculture: Revisited. Agricultural Economics Research Review, 18:317324. https://DOI:10.5958/0974-0279.2019.00001.6

5. Rajarathinam, A., Parmar, R.S. \& Vaishnav, P.R. (2010). Estimating Models for Area, Production and Productivity Trends of Tobacco (Nicotiana tabacum) Crop for Anand Region of Gujarat State. Indian Journal of Applied Sciences, 10:2419-2425. https:// DOI; $10.15373 / 2249555 X$

6. Singh, P.S.; Adarsha, L.K., Nandi; A.K. andJopir, O. (2018). Production Performance of Fresh Mango in India: A Growth and Variability Analysis. International Journal of Pure Applied Biosciences, 6(2):935- 941. https:// DOI: 10.18782/2320-7051

7. Singh, Rajender; Kumar, Manoj; Dahiya, Mamta and Baloda, Satpal (2019). Development of growth model for Ber powdery mildew in relation to weather parameters. Indian Phytopathology. pp1-7 72(1). https:// doi.org/10.1038/164690b0

8. Kumar, Manoj; Battan, K.R. and Sheoran, O.P. (2019). Pre-harvest forecast model for rice yield using principal component regression based on biometrical character with R-software. Int. J. Agricult. Stat. Sci.,15, (1): 323-326 https:// doi:10.1029/20 08WR007163.

9. Mukherjee, Deep Naryana; Vasudev, N; Sushasini,K.; and Kumari, R. Vijaya (2016). Application of nonlinear growth models for estimation for annual compound growth rates of major pulse crops in the Telangana State.. The J. Res. PJTSAU 44(1\&2)2733 https:// doi: 10.3389/fphys.2015.00119 